\title{
EROSIVITY INDICATORS BASED ON RAINFALL IN NORTHWESTERN MEXICO
}

\author{
Mariano NORZAGARAY-CAMPOS ${ }^{a}$, Patricia MUÑOZ-SEVILLA ${ }^{\mathrm{b}}$, Leticia ESPINOSA-CARREÓNa, \\ Rosario RUÍZ-GUERREROc ${ }^{c}$, Héctor GONZÁLEZ-OCAMPO ${ }^{a}$, Omar LLANES-CÁRDENAS ${ }^{a}$
}

\author{
${ }^{a}$ Instituto Politécnico Nacional-CIIDIR-Sinaloa, Blvd. Juan de Dios Bátiz Paredes No. 250, \\ Colonia San Joachín, Guasave Sinaloa, México CP:81101 \\ ${ }^{b}$ Instituto Politécnico Nacional - CIIEMAD, Calle 30 de Junio de $1520 \mathrm{~s} / \mathrm{n}$, \\ Barrio la Laguna Ticomán C.P. 07340 Del. Gustavo A. Madero, Ciudad de México, México \\ 'Instituto Politécnico Nacional- CIITEC, Cerrada de Cecati S/N. Col. Santa Catarina Azcapotzalco \\ Ciudad de México, México CP: 02250
}

Submitted 24 Nov. 2014; accepted 07 Oct. 2015

\begin{abstract}
This study is motivated by the problem of erosivity $(R)$, exacervated in semiarid zones by intense seasonal storms. The purpose was to estimate the spatial variation of $R$ in a coastal area covering $37500 \mathrm{~km}^{2}$ which is one of the most important agricultural areas in northwestern Mexico. Four methods were used. Rainfall data from 11 SMNCONAGUA weather stations (from 1966 to 2013) were used to calculate $R$. The annual average $R_{1}$ was 1181.08 , and $R_{2}$ was $1084.51 \mathrm{MJ} \mathrm{mm} \mathrm{ha}{ }^{-1} \mathrm{~h}^{-1}$ with ranges of 2.35-5220.55 and 2.93-4711.38 MJ mm ha $\mathrm{m}^{-1}$. Statistical tests showed that a transformation of the data of the form $y=\log (x)$, was appropriate for an ANOVA analysis of the data. The value of the test statistic was $F=1.77$ with $p=0.149$, showing interdependence between the indicators $P(\alpha=0.05)$. The values of the correlation coefficients for the data were $P$ vs. $R_{1}=0.96, P$ vs. $R_{2}=0.99, P$ vs. $A I_{m}=0.98, P$ vs. $M F I=0.99$. The classification of risk in this region showed that $2017.5 \mathrm{~km}^{2}$ of the study area was at a very high risk of rain erosion, $2407.5 \mathrm{~km}^{2}$ under high risk, $5662.5 \mathrm{~km}^{2}$ under medium to high risk, and $14250 \mathrm{~km}^{2}$ under low risk. The results are shown on 1:10,000 maps. Results are a set of useful information for soil management programs and for cultivation planning that takes the seasonal variation of $R$ into account in this region where large volumes of extensive crops are grown.
\end{abstract}

Keywords: rainfall, risk, indicators, semiarid zones, coastal area.

\section{Introduction}

Preventing tillage, wind, and the erosive force of rain from reducing soil fertility and degrading the cultural record depends to some degree on successful management of agricultural and forest resources and of water resources to reduce the loss of sediments (FAO 2015; Morgan 2005). A major factor determining soil erosion processes by water is the erosive potential caused by raindrop impact. This issue is of special interest in the agriculture and forestry industries due to the harmful effects of rain erosion on the soil. It is also a key agent in the process of sediment production. Many models have been developed for studying raindrop erosivity $(R)$ and its properties. Parameters such as intensity, speed, size, and kinetic energy are commonly used to develop indexes describing the behavior of $\mathrm{R}$. Among indicators of $R$, the most common algorithms are: (1) the universal soil loss equation (USLE) $\left(R_{1}\right)$, recognized as one of the best parameters for predicting erosive potential by raindrop impact (Muñoz et al. 2011; Oñate 2004; De Santos, De Azevedo 2001); (2) regression curves calculated from empirical pluviographic and pluviometric data for each region $\left(R_{2}\right)$ (Martínez 2005; Pérez, Mesa 2002); (3) the modified Fournier index, better known as climate aggressiveness (MFI) (Yuksel et al. 2008) and (4) the Lal index $\left(A I_{m}\right)$ or rainfall erosivity (Lal 1976). Throughout the world, determining the behavior of $R$ is a problem related to climate, especially in agricultural areas where it implicitly has both an environmental and economic impact (Arshad, Martin 2002).

\footnotetext{
Corresponding author: Patricia Muñoz Sevilla

E-mail: npmsevilla@gmail.com
} 
In northwestern Mexico, three of the most important agricultural valleys; Guasave Valley, El Fuerte Valley and Mocorito Valley, are intensely cultivated. Erosion produced by misuse of the soil has been reported to be an important environmental problem (Llanes et al. 2011).

This, together with the additional factor of intense rainfall $(P)$, motivated the present study. The goal is to estimate $R$ by the four indexes listed above. To date, there have been no studies of the progress of erosion, so it is not known how potential soil loss scenarios might play out in the region. The height of the rainy season (July to September) is a particularly critical period. Furthermore, the absence of any sediment management plans (soil use plans, for example), makes it difficult to counteract erosion and favors factors that promote it. It is important to note that this study was carried out in a region where large volumes of corn, tomatoes, potatoes and other crops of great domestic and international importance are grown. As in other parts of the world, the population explosion and the sharp increase in agriculture and trade in recent years have stimulated a set of environmental problems that have increased erosion levels directly related to structural soil stability (Núñez et al. 2007; Llanes et al. 2013). The results of this study will provide soil users with a fundamental understanding of the agents that govern sediment production processes. Finding the spatial distribution of $R$ and its risks will enable the development of strategies to reduce erosivity in both coastal and mountain environments in this region which is influenced by the dynamics of climate, topography, vegetation and other factors that favor erosion.

\section{Materials and methods}

The methodologies for measuring indicators of spatial variation of $R$ were applied to an area covering approximately $37500 \mathrm{~km}^{2}$ in northwestern Mexico. The study area included various hydric conditions and extensive coastal plains with typical rainy seasons from July to September. The main water tributaries are the Sinaloa, El Fuerte and Mocorito Rivers. They arise in the Sierra Madre Mountains in Chihuahua State where the Mohinora and Basoapa currents join (Toutcha et al. 2005). After approximately $380 \mathrm{~km}$, they empty into the Gulf of California with annual average rates of flow $(Q)$ of 700 to $2,240 \mathrm{~m}^{3} \mathrm{~s}^{-1}$. The high carrying capacities of these rivers readily transport their sediment loads to the final destination. In particular, the sediments of the Sinaloa River are freely carried to its delta due to the dredging carried out by the state government in 2013 that put an end to the problem of accumulated sediments, but increased output of the products of continuous erosion. There are other secondary tributaries; Arroyo De Cabrera, De Ocoroni and De San Rafael, which with their respective flow rates of 18 to $25,12.3$ to 15.2 and 125 to $150 \mathrm{~m}^{3} \mathrm{~s}^{-1}$ also transport sediment loads (Fig. 1).

Pluviographic and pluviometric data from 1966 to 2013 were obtained from weather Data Base Northwest México of SMN-CONAGUA (Mexican National Meteorological Service-Mexican National Water Commission). The $R_{1}$ index was calculated by the method of Almoza et al. (2007), $R_{2}$ was calculated using the logarithmic algorithm of Pérez, Mesa (2002). The $A I_{m}$ index

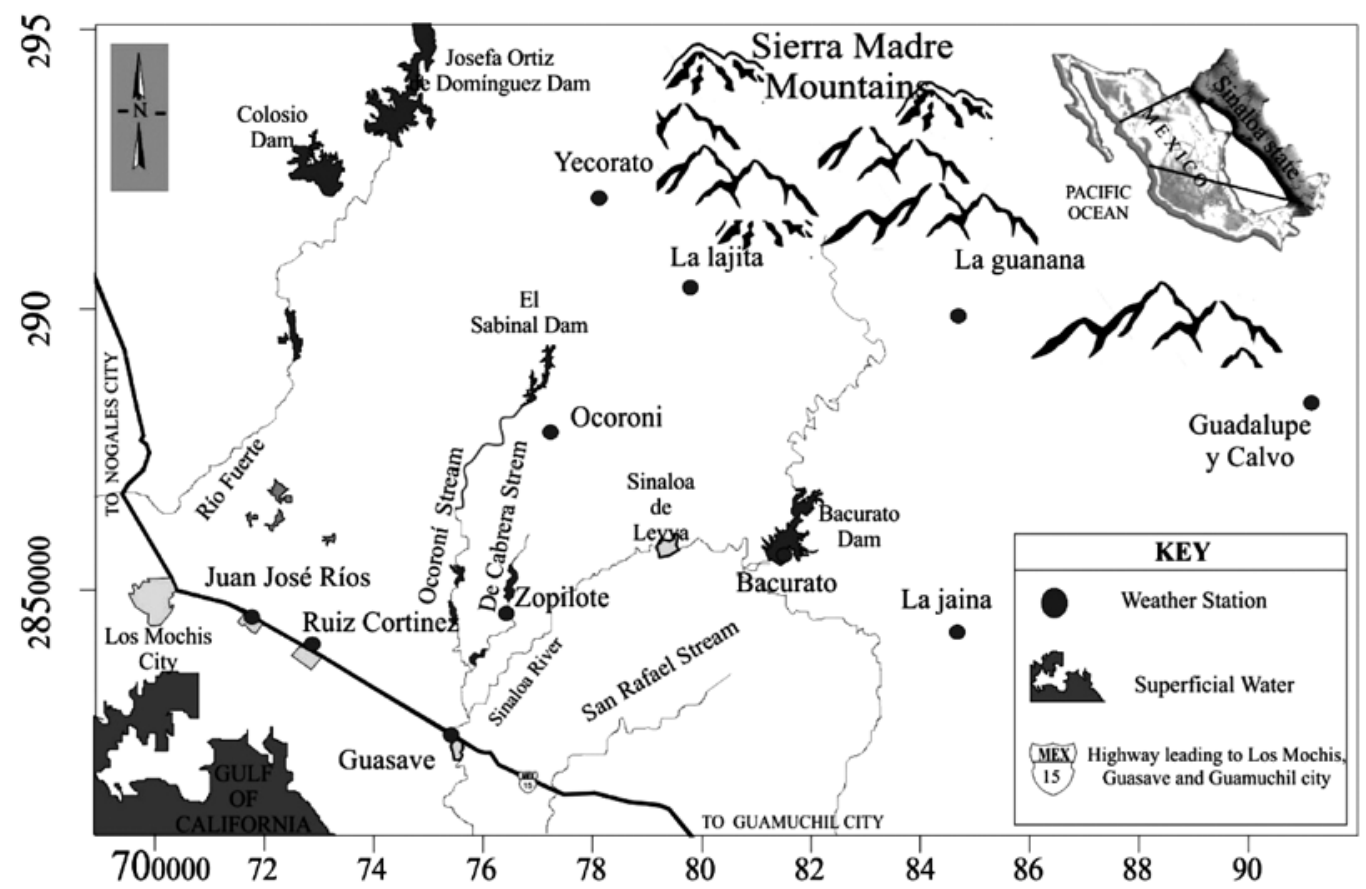

Fig. 1. Location of study area 
(rainfall erosivity) was calculated using the method of Lal (1976):

$$
A I_{m}=\sum_{J=1}^{12}\left[\sum_{1}^{n} a I_{\max }\right], i=1, \ldots, 12
$$

where $a$ was daily rainfall $(\mathrm{cm}), I_{\text {max }}$ the maximum intensity of rainfall at 7 minutes $\left(\mathrm{cm} \mathrm{h}^{-1}\right), n$ the number of storms in a month and $i$ indicates the month. The MFI index or climate aggressiveness was calculated by the method of Yuksel et al. (2008):

$$
M F I=\frac{\sum_{i=1}^{12} P^{2}}{p_{i}}, \quad i=1, \ldots, 12 ;
$$

where $P_{i}$ was the mean monthly rainfall $(\mathrm{mm})$ and $p^{2}$ the mean annual rainfall. The variables used for the estimates $R_{1}$ and $R_{2}$ were total kinetic energy of rain $(E)$ in $\mathrm{MJ} \mathrm{ha}^{-1}$ and the maximum intensity of each storm at 30 minutes $\left(I_{30}\right)$ in $\mathrm{mm} \mathrm{h}^{-1}$ (Khosrowpanah, Leroy 2001). $R_{2}$ was calculated using the intensity of rainfall and/or a specific increase of rain in pluviophase $k(\Delta i k)$, and the period of increase of the storm or duration of the pluviophase $k\left(\Delta t_{k}\right)$, both in $\mathrm{mm} \mathrm{h}^{-1}$ (for more information see Almoza et al. 2009). Using pluviographic data, the number of downpours per year $(n)$, the pluviophase of the downpours $(q)$ and unit kinetic energy $(e k=k)$; or kinetic energy per $\mathrm{mm}$ of rain $\left(\mathrm{MJ} \mathrm{ha}^{-1} \mathrm{~mm}^{-1}\right)$ were determined. For $E$, the logarithmic regression $E=a+b \log _{10} I_{j}$ proposed by Elaheh et al. (2012) was used, for which the constants $a$ and $b$ and the intensity of $P\left(I_{j}\right)$ in $\mathrm{mm} \mathrm{hr}^{-1}$ were estimated. The $A I_{m}$ index $\left(\mathrm{cm}^{2} \mathrm{~h}^{-1}\right)$ was calculated using daily $P(a)$ in $\mathrm{cm}$, maximum intensity of the rain for 7 minutes in $\mathrm{cm} \mathrm{h}^{-1}$ $\left(I_{\max }\right)$ and the number of downpours per month $(n)$; and for the MFI index, $P$ and its monthly average $\left(p^{2}\right)$, both in $\mathrm{mm}$, were used. The criteria of Da Silva (2004) were used to classify the risk of $R$ by means of $R_{1}$ and $R_{2}$. The classes were: very low $<2452$, low $2452-4905$, moderate $4905-$ 7357 , high 7357-9810, and very high $>9810$. To compare the annual average of $R_{1}$ and $R_{2}$ to values in other regions of the world, the ranges shown in Table 1 were used.
To classify risk based on MFI values, the categories of Lobo, Gabriels (2005) were applied: 0-60 very low, 60-90 low, 90-120 moderate, $120-160$ high, >160 very high. Based on the relationship between the spatial variance of MFI and of $A I_{m}$ (Almoza et al. 2007), the following classification was proposed for MFI: very low 0-100, low 100-200, moderate 200-450, high 450-1050, and very high $>1050$.

A statistical analysis was performed to compare the behavior of $P$ with respect to the four indicators. The Shapiro-Wilk test was applied to test for normality in the distributions of the indicators, with significance level $a=$ 0.05. As all the distributions were found to be skewed, the transformation $y=\log (x)$ was applied to the data in order to make a linear model appropriate and enable estimates of the respective correlations between the dependent variables $\left(R_{1}, R_{2}, M F I\right.$ and $\left.A I_{m}\right)$ and $P$ to be calculated. To determine whether there were significant differences, a one-factor ANOVA test was applied with five levels, at a significance level of $\alpha>0.05$. Groups that showed a difference in the ANOVA $(F>1, p<0.05)$, were tested using a Tukey HSD (Honestly Significant Difference) test, using the criterion 0.05 (95\%). For the ANOVA analysis, the PAST $2.17 \mathrm{~b}$ program (Hammer et al. 2001) was used and corroborated with the IBM SPSS Statistics 2.1 program (IBM 2012).

The maps were drawn on a scale of 1:10,000 in geographic coordinates (UTM), using kriging interpolation in the SURFER 10.0 program (Emery 2007) and a spatial variation in two regions (UTM: Zone 12 and 13). To represent these two zones, the distance between one station in Zone 12 and another in Zone 13 was measured and added to the initial coordinate, to provide continuity to the interpolations. The maps were finished using CorelDRAW X7.

\section{Results and discussion}

The averages of $P, P^{2}$ and $a$ were $753.31 \mathrm{~mm}^{-1}$ year $^{-1}$, $62.77 \mathrm{~mm}$ month $^{-1}$ and $2.09 \mathrm{~mm} \mathrm{day}^{-1}$ respectively, and their ranges of variation were 70.9-2174.5 $\mathrm{mm} \mathrm{year}^{-1}$,

\begin{tabular}{|c|c|c|c|c|}
\hline \multicolumn{5}{|c|}{ Rainfall erosivity $(R)$} \\
\hline Country & Region & $\begin{array}{l}\text { Maximum Value } \\
\left(\mathrm{MJ} \mathrm{mm} \mathrm{ha} \mathrm{h}^{-1} \mathrm{~h}^{-1}\right)\end{array}$ & $\begin{array}{l}\text { Minimum Value } \\
\left(\mathrm{MJ} \mathrm{mm} \mathrm{ha}^{-1} \mathrm{~h}^{-1}\right)\end{array}$ & Author \\
\hline Ecuador & Ucabanba and San Cristóbal & $1,140.3$ & $1,231.4$ & Suffis 2004 \\
\hline Portugal & Flanders & 20 & $3,741.8$ & De Santos, De Azevedo 2001 \\
\hline Brazil & Center of Brazil & 20,000 & 24,000 & Da Silva 2004 \\
\hline Colombia & Caldas Department & 800 & 860 & Ramírez, Hincapié 2009 \\
\hline Chile & Curicó Valley & 180 & 285 & Mancilla 2008 \\
\hline Cuba & Cuyaguateje Valley & 8,200 & 18,000 & Almonza 2007 \\
\hline Spain & Provinces of Córdoba, Jaén and Cadiz & 40 & 600 & De la Rosa, Moreira 1987 \\
\hline
\end{tabular}

Table 1. Average annual variation of rainfall erosivity $(R)$ for comparison of $R_{1}$ and $R_{2}$ with other regions of the world (MJ mm ha-1 $\left.\mathrm{h}^{-1}\right)$ 
8.90-181.20 mm month ${ }^{-1}$ and 0.74-6.04 $\mathrm{mm} \mathrm{day}^{-1}$ respectively. Rainfall in the wettest months, July, August and September, with annual monthly averages of $6.09,113.27$ and $143.97 \mathrm{~mm}$ year $^{-1}$, accounted for $78.8 \%$ of total $P$. February, March, April and May, with $3.6 \%$ average annual rainfall, were the driest months (Fig. 2, part A). During the course of the year, $n$ varied and was directly proportional to $P$. The highest rainfall occurred during the wettest months and was moderate to low along the coast, moderately low to high in the agricultural area and highest in the Sierra Madre Mountains.

A total of 70 downpours were recorded at six weather stations in the Sierra Madre Mountains; 25 at three coastal stations and 20 at two stations in the central agricultural region. Given that rain is the main cause of damage to structural stability of the soil during the first few minutes of a downpour, the values of $n$ were used as a first approximation of the susceptibility of the soil to erosivity $(R)$ (Núñez et al. 2007) and thus as a first indicator of the expected value of $R_{1}, R_{2}, M F I$ and $A I_{m}$ (Fig. 2, part
B). The average annual values of $I_{30}$ and $I_{\max 7}$ were 20.72 and $4.8 \mathrm{~mm}$ year ${ }^{-1}$ and the ranges of variation in daily values were $15-30$ and $3.5-7 \mathrm{~mm}$. The ranges of $\Delta i k$ and $\Delta t_{k}$ were $2.4-3.45 \mathrm{~mm} \mathrm{~h}^{-1}$ and 1.54-3.22 hours, and the average annual $e_{k}=k$ per mm of rain was $0.105-114 \mathrm{MJ}$ $\mathrm{ha}^{-1} \mathrm{~mm}^{-1}$. These environmental conditions in the region produced rainy, stormy weather with spatial variation in $E$ from 211 to $4474.60 \mathrm{MJ} \mathrm{ha}^{-1}$ and an annual average of 1105.47 $\mathrm{MJ} \mathrm{ha}^{-1}$. This indicates high $P$ and a high expected value for $R$ (Fig. 2, part C). The variation of $E$ is shown in part $C$ of Figure 3. In the eastern part of the study region, values of $E$ were small; they were larger in the central area and intermediate in the west. The Guanana and Bacurato weather stations recorded the highest values. Note in Figure 3 that the variation of $E$ is similar to that of $n$ and $P$, suggesting that the spatial variance of these variables is correlated (Chica 2005).

Six stations in hilly country and in the Sierra Madre Mountains had a variance of 0.99 (Yecorato, La Lajita, Guanana, Bacurato, Jaina and Guadalupe y Calvo), three
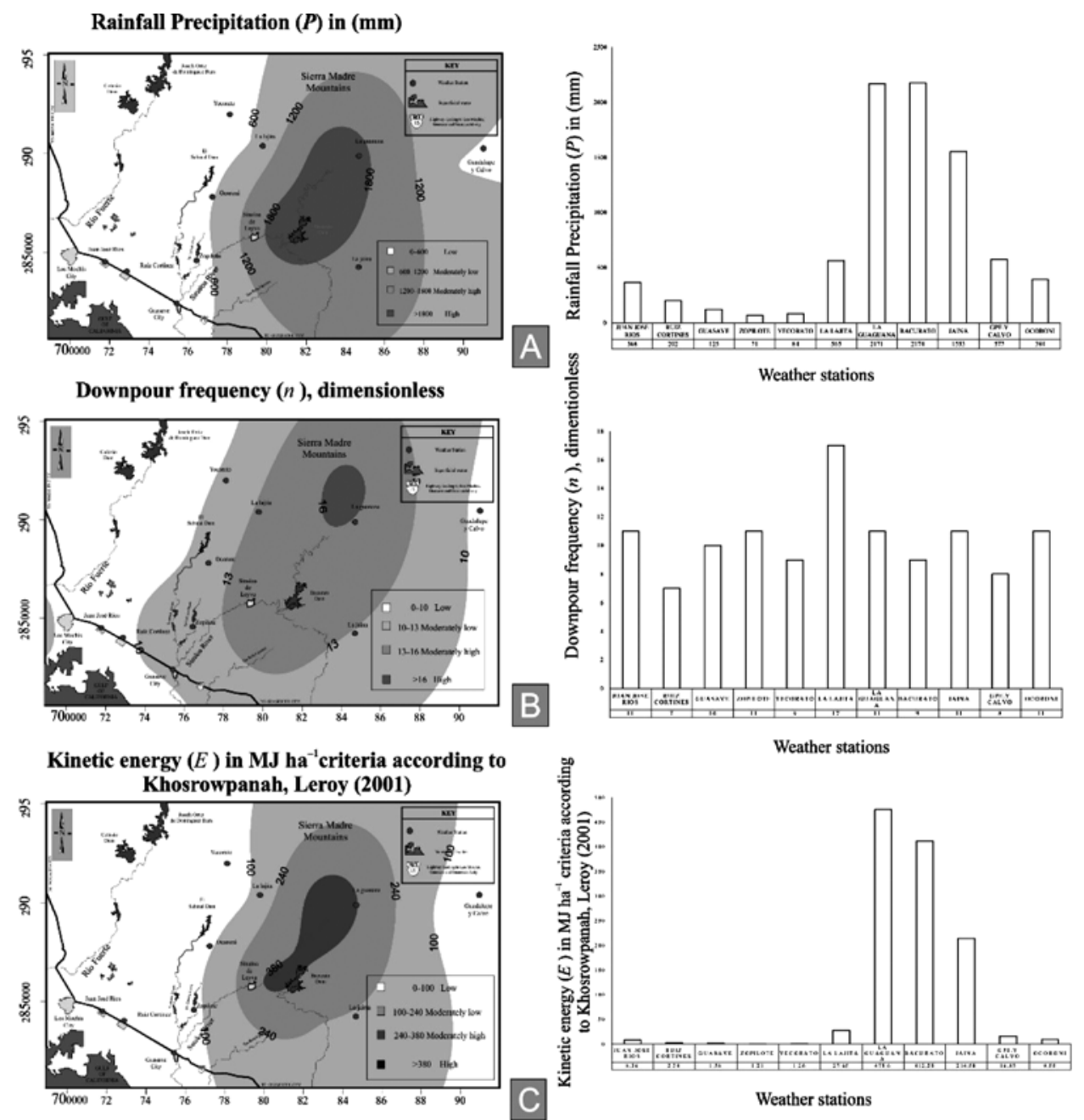

Fig. 2. (A) Spatial variation of annual average rainfall $(P)$ in $\mathrm{mm}$, (B) Spatial variation of annual numbers of downpours $(n)$ and $(C)$ total kinetic energy $(E)$ of rainfall in $\mathrm{MJ} \mathrm{ha}^{-1}$ in northwestern Mexico 
weather stations on the coast had a variance of 0.007 (Juan Jose Ríos, Ruiz Cortínez and Guasave), and two stations in the agricultural region also had a variance of 0.007 (Zopilote and Ocoroni). The high values of $n, E$ and $P$ from localities at higher elevation are $99 \%$, indicative of expected high values for $R$, particularly during the rainiest months. However, considering that $R$ is based not only on the amount of rainfall, but also on the intensity of $I_{\max 7} I_{30}$ and $E$, high values of $R$ in the agricultural and coastal areas cannot be ruled out. The average annual value of $R_{1}$ was 1161.30 and of $R_{2} 1084.51 \mathrm{MJ} \mathrm{mm} \mathrm{ha}{ }^{-1} \mathrm{~h}^{-1}$, with ranges 2.4-3701.2 and 2.93-4081.1 MJ mm ha ${ }^{-1} \mathrm{~h}^{-1}$ respectively. As shown in Table 1 , where these results are compared to values from other regions in the world, these results are similar to those found by Suffis (2004) for Ecuador (Ucabanba and San Cristobal) with annual averages of 1140.3-1231.4 MJ mm ha ${ }^{-1} \mathrm{~h}^{-1}$. Considering the influence of the climate, which is less influential than $P$, and except for values from Brazil where rainfall amounts are high (Da Silva 2004), the annual averages of $R_{1}$ and $R_{2}$ from northwestern Mexico can be considered high. The spatial variations of $R_{1}$ and $R_{2}$ are shown on maps $A$ and $B$ in Figure 4, and it can be seen that with a variance of 0.98 in the indicators, they are quite similar, as are $E, P$ and $n$. The small differences between the maps in Figure 4 were attributed to use of the appropriate logarithmic regression equation that determined $E$ and which was represented by the constants $a=0.32$ and $b=2.08$.

The average annual MFI was $130.30 \mathrm{~cm}^{2} \mathrm{~h}^{-1}$ and $A I_{m}$ $781.78 \mathrm{~mm}$. Their ranges were $14.1-362.56 \mathrm{~cm}^{2} \mathrm{~h}^{-1}$ and $84.50-2175.22 \mathrm{~mm}$ respectively. The values of $A I_{m}$ and
MFI are shown in Figure $5 \mathrm{~A}$ and B. As in the maps of $R_{1}$ and $R_{2}$, there is a spatial pattern in which values are lower in the east, higher in the central area, and intermediate in the west. The Bacurato and Guanana stations showed the highest values. The fraction of $A I_{m}$ and $M F I$ is analogous to the fraction of $R_{1}$ and $R_{2}$ in most seasons, as would be expected. The areas where each indicator reached its with the highest risk to the soil as indicated by $R$. These were the places with the highest values of annual precipitation and the heaviest downpours. In the total $37,500 \mathrm{~km}^{2}$ study area, using the criteria of $\mathrm{Da}$ Silva (2004), the risk as measured by $R_{1}$ indicates that $5.38 \%$ of the region $\left(2017.5 \mathrm{~km}^{2}\right)$ has a high to very high risk of erosion by rain, $6.42 \%\left(2407.5 \mathrm{~km}^{2}\right)$ a medium to high risk, $15.1 \%\left(5662.5 \mathrm{~km}^{2}\right)$ a low to medium risk, $38.2 \%\left(14325 \mathrm{~km}^{2}\right)$ low risk and $34.9 \%\left(13087.5 \mathrm{~km}^{2}\right)$ a very low risk. In terms of $R_{2}$, the percentage of high to very high was $10.2 \%\left(3825 \mathrm{~km}^{2}\right), 14.7 \%$ medium to high $\left(5512.5 \mathrm{~km}^{2}\right), 13.7 \%$ low to medium $\left(5137.5 \mathrm{~km}^{2}\right), 23.2 \%$ low $\left(8700 \mathrm{~km}^{2}\right)$ and $38.2 \%$ very low $\left(14325 \mathrm{~km}^{2}\right)$. The results obtained for $A I_{m}$ using the territorial classification of Lobo, Gabriels (2009) were 38\% very low risk $\left(14250 \mathrm{~km}^{2}\right), 31.2 \%$ low $\left(11700 \mathrm{~km}^{2}\right), 13.5 \%$ moderate $\left(5062.5 \mathrm{~km}^{2}\right), 12.3 \%$ high $\left(4612.5 \mathrm{~km}^{2}\right)$ and $5 \%$ very high risk $\left(1875 \mathrm{~km}^{2}\right)$. Using $M F I, 28 \%$ of the area $\left(10500 \mathrm{~km}^{2}\right)$ was classified as very low risk, $24.7 \%$ low $\left(9262.5 \mathrm{~km}^{2}\right)$, $20.3 \%$ moderate $\left(7612.5 \mathrm{~km}^{2}\right), 15 \%$ high $\left(5625 \mathrm{~km}^{2}\right)$ and $12 \%\left(4500 \mathrm{~km}^{2}\right)$ very high risk. The results of the statistical analysis are presented in Table 2 , showing that $P$ spatially resembles $R_{1}, R_{2}, A I_{m}$ and $M F I$. The Shapiro-Wilk
Erosivity indicator $\left(\boldsymbol{R}_{l}\right)$ criteria acording Laureano (2001) (USLE model), MJ mm ha ${ }^{-1}{ }^{-1}$.

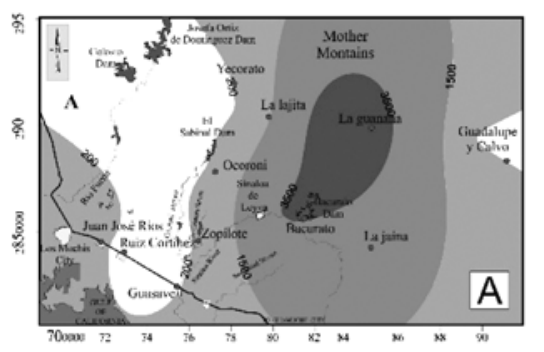

Erosivity indicator $\left(R_{2}\right)$ criteria acording Martínez (2005); Pérez and Meza (2002) pluviogrhapics datas, MJ mm ha ${ }^{-1} \mathrm{~h}^{-1}$.

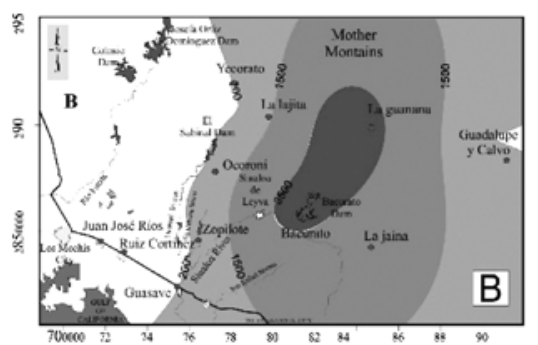

$\square$ Erosivity indicator $\left(R_{i}\right)$, criteria according to USLE $\left(R_{i}\right),\left(\mathrm{MJ} \mathrm{mm} \mathrm{ha} \mathbf{m}^{-1} \mathrm{~h}^{-1}\right)$

- Erosivity indicator $(R)$, criteria according to Elaheh et al. 2012; Martínez (2005); Pérez, Mesa (2002): with pluviographic data (MJ mm ha ${ }^{-1} \mathrm{~h}^{-1}$ ).

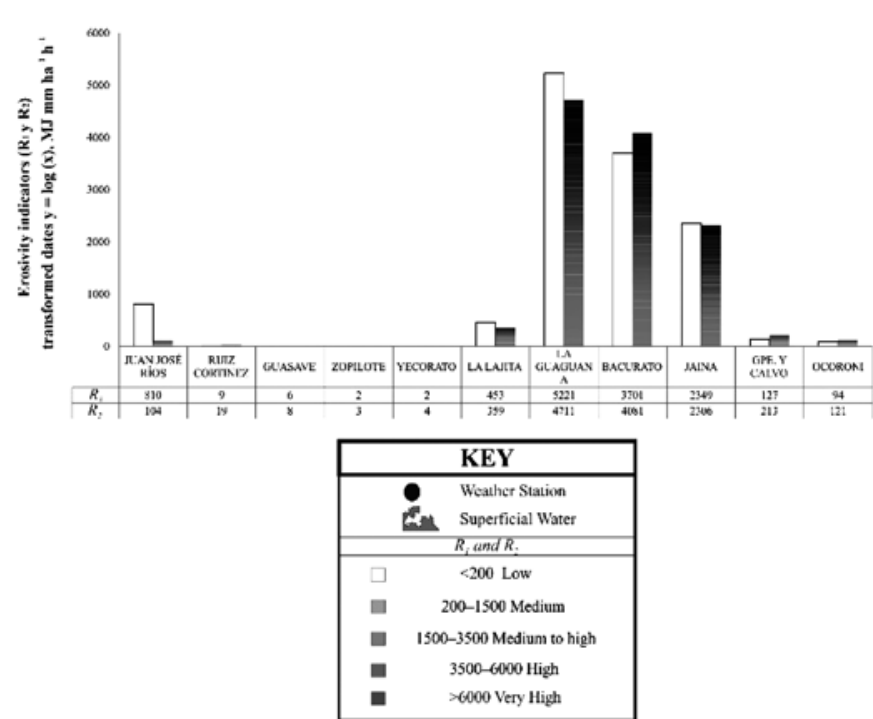

Fig. 3. (A) Spatial variation of annual average factors of rainfall erosivity according to USLE $\left(R_{1}\right)$, (B) annual average factor of erosivity according to the curves of logarithmic regressions $\left(R_{2}\right)$ both in $\mathrm{MJ} \mathrm{mm} \mathrm{ha}^{-1} \mathrm{~h}^{-1}$ and their respective ranges of risks for soils in northwestern Mexico 


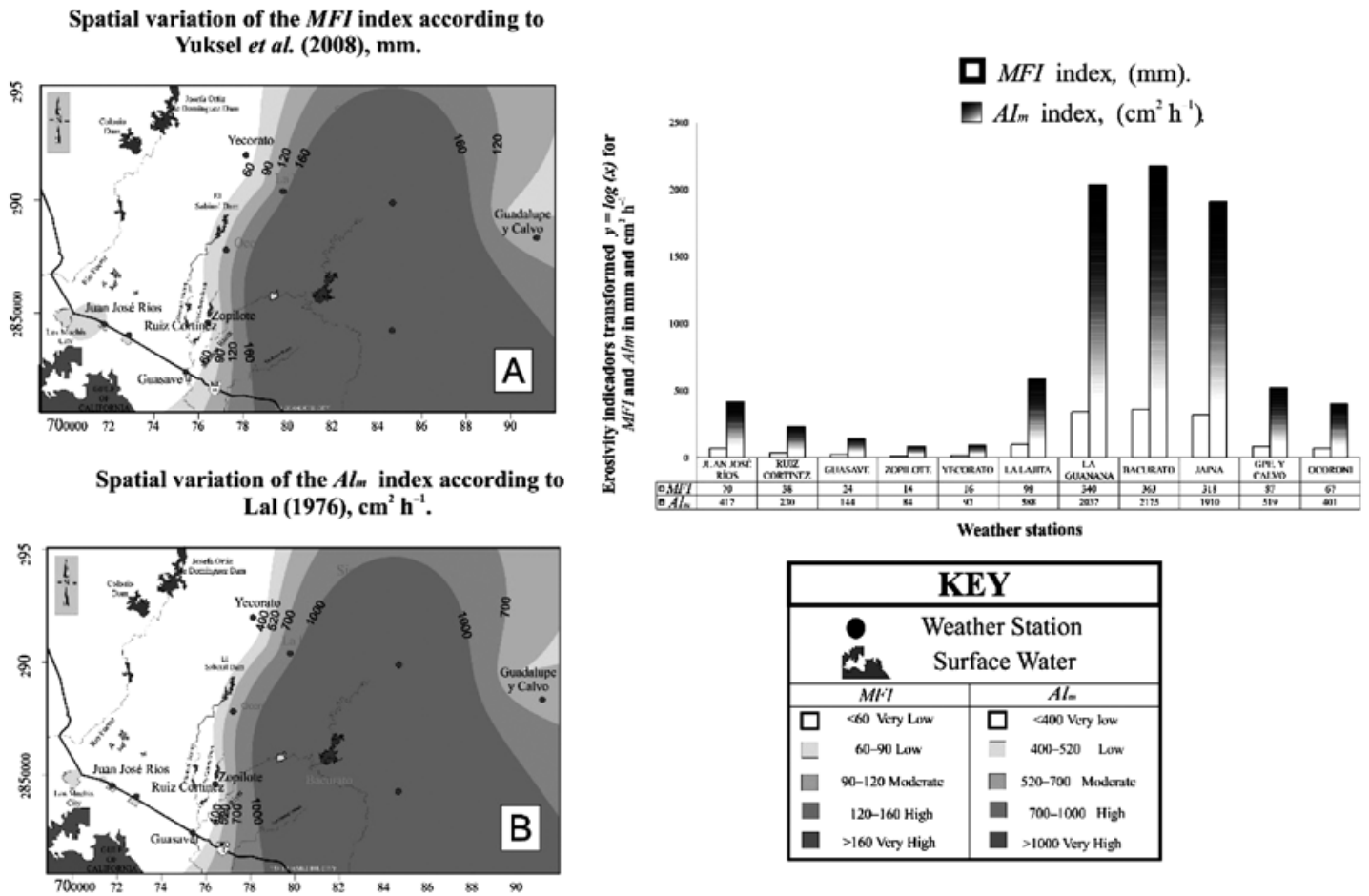

Fig. 4. Spatial variation of the $M F I$ index $(\mathrm{mm})$ and $A I_{m}$ index $\left(\mathrm{cm}^{2} \mathrm{~h}^{-1}\right)$

Table 2. Magnitude of annual average precipitation $(P)$ in $\mathrm{mm}$, annual averages of indicators of erosivity: $R_{1}\left(\mathrm{MJ} \mathrm{mm} \mathrm{ha}^{-1} \mathrm{~h}^{-1}\right), R_{2}(\mathrm{MJ}$ $\left.\mathrm{mm} \mathrm{ha}^{-1} \mathrm{~h}^{-1}\right), A I_{m}\left(\mathrm{~cm}^{2} \mathrm{~h}^{-1}\right)$ and MFI $(\mathrm{mm})$ and ANOVA results in northwestern Mexico.

\begin{tabular}{|c|c|c|c|c|c|c|}
\hline Number & Weather Station & $\boldsymbol{P}\left(\mathrm{mm}\right.$ year $\left.^{-1}\right)$ & $\boldsymbol{R}_{\boldsymbol{I}}\left(\mathrm{MJ} \mathrm{mm} \mathrm{ha} \mathrm{m}^{-1} \mathrm{~h}^{-1}\right)$ & $\boldsymbol{R}_{2}\left(\mathrm{MJ} \mathrm{mm} \mathrm{ha} \mathrm{mi}^{-1} \mathrm{~h}^{-1}\right)$ & MFI (mm) & $A l_{m}\left(\mathrm{~cm}^{2} \mathrm{~h}^{-1}\right)$ \\
\hline 1 & Juan José Ríos & 368 & 810 & 104 & 70 & 417 \\
\hline 2 & Ruiz Cortínez & 202 & 9 & 19 & 38 & 230 \\
\hline 3 & Guasave & 125 & 6 & 8 & 24 & 144 \\
\hline 4 & Zopilote & 71 & 2 & 3 & 14 & 84 \\
\hline 5 & Yecorato & 84 & 2 & 4 & 16 & 93 \\
\hline 6 & La Lajita & 565 & 453 & 359 & 98 & 588 \\
\hline 7 & La Guanana & 2171 & 5221 & 4711 & 340 & 2037 \\
\hline 8 & Bacurato & 2174 & 3701 & 4081 & 363 & 2175 \\
\hline 9 & La Jaina & 1553 & 2349 & 2306 & 318 & 1910 \\
\hline 10 & Gpe. y Calvo & 577 & 127 & 213 & 87 & 519 \\
\hline 11 & Ocoroni & 394 & 94 & 121 & 67 & 401 \\
\hline \multicolumn{7}{|c|}{ One-way ANOVA } \\
\hline & & Sum of sqrs & $d f$ & Mean Square & $F$ & $\mathrm{p}$ (same) \\
\hline & Between groups: & 5.469 & 4 & 1.367 & 1.772 & 0.149 \\
\hline & B Within groups: & 38.589 & 50 & 0.772 & & \\
\hline & Total: & 44.058 & 54 & & & \\
\hline & Omega $^{2}:$ & 0.0531 & & & & \\
\hline
\end{tabular}

Levene's test for homogeneity of variance, based on means: $p$ (same) $=0.00062$

Based on medians: $p$ (same) $=0.00072$

Welch $F$ test in the case of unequal variances: $F=3.961, d f=24.45, p=0.01293$ 
test was applied to test for a normal distribution, $\alpha<$ 0.05 . The resulting test statistics and significance levels were: $R_{1}(W=0.714, p=0.0007), R_{2}(W=0.663, p=$ $0.0002), M F I(W=0.756, p=0.0025)$ and $A I_{m}(W=0.755$, $p=0.0024)$, indicating that none of the indices were normally distributed. The data were therefore transformed by $y=\log (x)(\alpha>0.05)$. A one-factor ANOVA test was applied to the transformed data. The resulting statistics were $R_{1}(W=0.905, p=0.21), R_{2}(W=0.925, p=0.36), M F I$ $(W=0.917, p=0.29), A I_{m}(W=0.916, p=0.28)$, supporting the $\log$ transformation for the data.

The value of the ANOVA test statistic was $F=1.772$ with $p=0.149$. Considering the established level for significant differences, a test statistic $>1$ indicated that means of the groups were not significantly different. However, since the $F$ statistic $>1$, the results of the Tukey HSD test indicated which of the estimated means were different. The results of the HSD test were: $\mathrm{t}(20)=4.16$, MSE (Mean square error) $=0.77$ and $\mathrm{HSD}=1.10$. The pairwise comparisons of HSD between indices were: $[P]$ vs. $\left[R_{1}\right]=0.553,[P]$ vs. $\left[R_{2}\right]=0.529,[P]$ vs. $[M F I]=0.746,[P]$ vs. $\left[A I_{m}\right]=-0.03,\left[R_{1}\right]$ vs. $\left[R_{2}\right]=-0.023,\left[R_{1}\right]$ vs. $[M F I]=$ $0.193,\left[R_{1}\right]$ vs. $\left[A I_{m}\right]=-0.583,\left[R_{2}\right]$ vs. $[M F I]=0.216,\left[R_{2}\right]$ vs. $\left[A I_{m}\right]=-0.559,[M F I]$ vs. $\left[A I_{m}\right]=-0.776$. Using the criterion of 0.05 (95\%) significance level in the pairwise comparisons, $[P]$ vs. $[M F I]$ and $[M F I]$ vs. $\left[A I_{m}\right]$ are the pairs with the highest differences between their averages, with HSD $=1.10$. The results of the ANOVA and Tukey tests show that the $80 \%$ of the results are dependent on $P$, and any differences observed can be attributed to random variation.

The correlation and interdependence between indicators of $R$ in the region are illustrated in Figure 5, where the graphs are the result of applying a multivariate linear model with four dependent variables characterized by the following coefficients of determination: $P$ vs. $R_{1}=0.91, P$ vs. $R_{2}=0.95, P$ vs. $A I_{m}=0.98, P$ vs. $M F I=0.97$.

Taking into account the spatial behavior of the results in this agricultural region of northwestern Mexico, farmers should schedule tillage and irrigation to prevent damage to the soil; that is, mainly during the months when $R$ is highest, which is manifested not only by the value of $P$, but also by the influence of $I_{30}, I_{\max 7}$ and $E$.

The rainfall in the region has a high erosive potential that is highest in the Guanana and Bacurato region, at elevations between 250 and 350 meters above sea level. This range is the source of both surface water and groundwater in the valley. The variations illustrated in the maps are of great utility for farmers since they indicate which places have greater and lesser $R$ risk and enable planning for sustainable agricultural systems, which is of great importance for the regional and national economy.

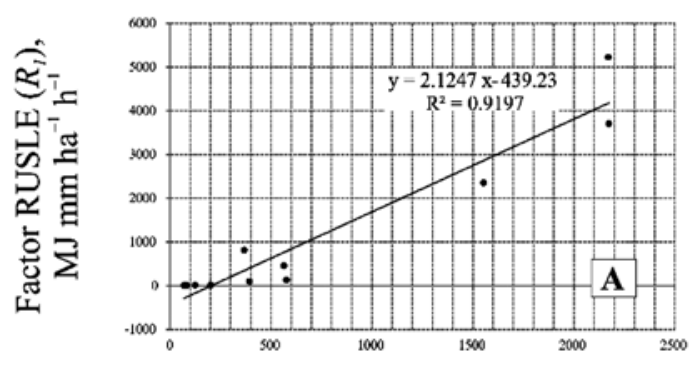

Annual average precipitation, $\mathrm{mm}_{\text {year }}{ }^{-1}$

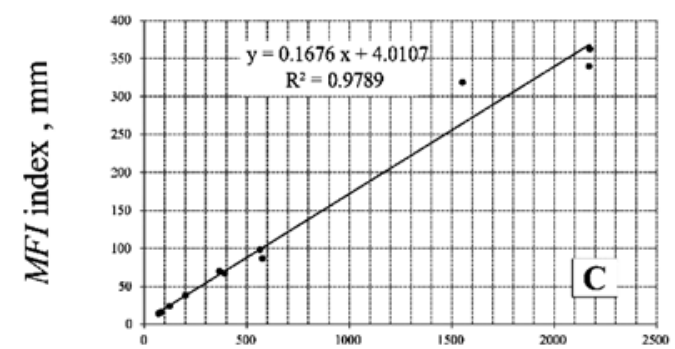

Annual average precipitation, $\mathrm{mm}$ year $^{-1}$
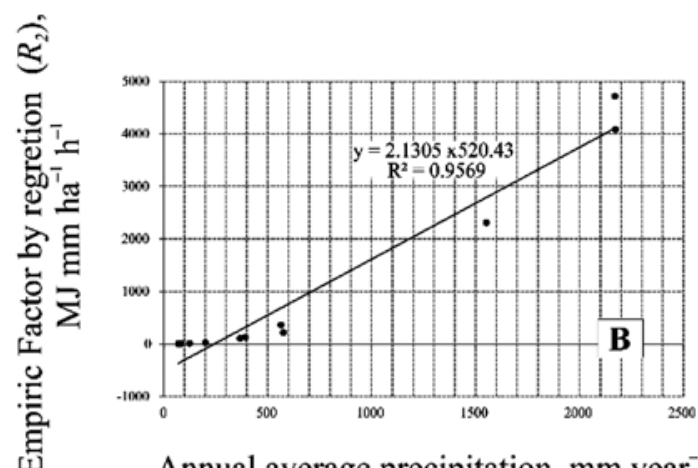

Annual average precipitation, $\mathrm{mm}_{\text {year }}{ }^{-1}$

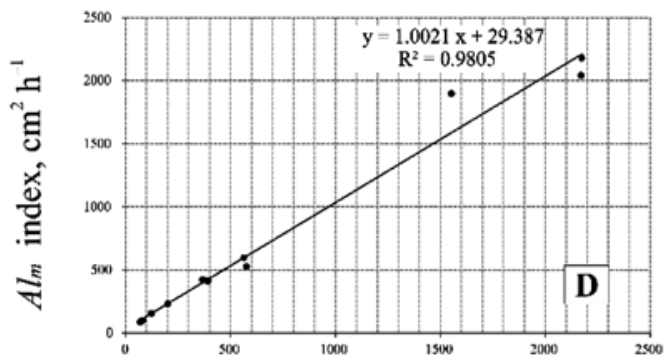

Annual average precipitation, $\mathrm{mm}_{\mathrm{mear}}{ }^{1}$

Fig. 5. Linear regression of annual average precipitation $(P)$ in $\mathrm{mm}$ with respect to indicators of erosivity: (A)

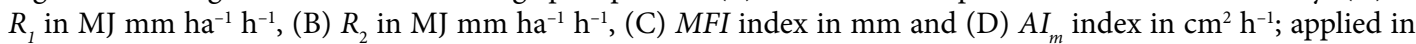
northwestern Mexico. 


\section{Conclusions}

The most important cause of degradation that puts soil fertility at risk is erosion caused by water (Zhu et al. 2011). It reduces sustainable sources of income in every country and threatens the principles of Conservation Agriculture (CA) (Morgan 2005). Any methodology that can contribute to conserving soil stability is important; and studies such as the present one that can define the erosivity risk of soils in a given agricultural region (here northwestern Mexico) enables management plans that can focus on the first of the three CA principles: (1) Direct planting of crop seeds with minimal mechanical disturbance of the soil; (2) permanent soil cover, especially by crop residues and cover crops and (3) crop diversity.

In spite of increasing interest in CA, there are still sustainable soil management approaches that focus mainly on an input-product approach. Studies such as the present one can help change this by directing attention to a comprehensive vision based on sustainable management. To achieve this, appropriate models and baseline indexes of erosion rates are required, which are rarely considered in developing countries (Seyed, Shahla 2015).

In the context of CA, the results of spatial variation of the four indicators in these agricultural valley regions enabled the areas with the largest values of $R$ to be identified. These coincided with the areas showing the greatest erosion problems, and vice versa. This reciprocal behavior between erosion and $R$ is attributed to the effect of other factors including the slope of the land, and soil texture and porosity. On the behavior of the slope, note in Figure 3 that in the west where $R$ is lower (agricultural area), gentle, rolling hills predominate. In the west where $R$ is higher (less erosion), there are steep, rugged slopes (mountainous areas). Integrating information from the four indicators that define soil risk in terms of $R$ enabled inference of the spatial nature of a phenomenon that is released in discrete "jumps" and is therefore highly energetic and damaging the longer it interacts with the soil system. Given these properties, the behavior of $R$ should be investigated in agricultural valleys around the world and at the same time validated by the methodology described here. The results obtained from applying this methodology can be used as a first indicator of soil loss. However, the reciprocal erosion-erosivity behavior points out the need to take other USLE factors into account in studies predicting total water erosion, as suggested by Wischmeier, Smith (1960). It is urgently recommended that this methodology be applied in areas with gentle slopes where large quantities of rain fall in a short time, in order to develop emerging plans for sites where $R$ is high, to recover the dynamic equilibrium of the soil and to conserve dynamic equilibrium where it is low, avoiding losses caused by high $E$ when raindrops fall on the soil. This is due to the fact that when $R$ is of long duration, the risk of breaking the dynamic equilibrium of the soil is greater than when $R$ is frequent and of short duration. When the soil system is broken, it is difficult to restore, and the losses that occur are irreversible. Considering that each system has a different threshold of resistance, that $R$ is different in each environment and if $R$ surpasses the soil resistance threshold it can result in loss, and that systems tend to evolve, it is important to know and monitor these thresholds in the agricultural valleys of the world. It is therefore important to quantify the risk and the spatial variation of $R$ - as in this study - in different scenarios around the world in order to carry out erosion management to control soil loss caused by rain, especially during rainy seasons. In light of this problem, appropriate measures should be taken to minimize the erosive effect of the rainy season, such as maintaining a permanent vegetative cover and refraining from working the land to remove or expose soil during the seasons of heaviest rain. In addition, further studies are needed to estimate $R$ at a finer scale. A monitoring network should be established involving more weather stations to provide indexes calculated from rainfall data and/or more complete pluviographic data to create a comprehensive specialized database that will enable numerical modeling of $R$ using geographic information systems and specialized software.

In this study, data from eleven weather stations were available, limiting the available data in time and space. Many parts of the world lack a suitable meteorological infrastructure to generate sufficient pluviographic and pluviometric data for such studies, making the necessary data difficult or impossible to obtain. This is commonly the situation in developing countries (Yu et al. 2001).

In some countries, the lack of daily and long term data on the intensity of precipitation means that any attempt to model soil erosion and sediment yield based on the USLE-R, USLE and RUSLE factors will be more difficult to calibrate and often inapplicable.

The calculation of actual values of $R$ depends on precise estimation of $E$ and $I_{30}$, and the original USLE and USLE-RUSLE method requires pluviographic and pluviometric records from numerous weather stations over a considerable amount of time for calculating $E I_{30}$. In this context, the present study had data that met these criteria in time but not in geographical distribution, which means that the estimates of $R$ are not as precise in space as might be desired. More weather stations should be established and monitored if future studies are to produce better estimates of $R$. The present study was designed following the criteria of Petrovsek, Mikos (2004), who stated that broad approximations can be made with the available data, so it was deemed feasible to proceed with the study and estimate the magnitude and behavior of $R$ in space with the existing data. However, it must be acknowledged that the results of this study reflect the variation of the available data in time and space. 
González et al. (2010) and Taguas et al. (2013) report for precipitation regimes in the Mediterranean zone, that high variability in long term records of rain intensity makes the treatment of data less appropriate for calculating the correct values of $R$. Analysis using data ranging over shorter periods tends to result in more accurate estimates of the behavior of $R$. Given this, future work should focus on the use of annual, monthly and daily pluviographic and pluviometric data, which is the form in which these data are normally reported (Shamshad et al. 2008). This is the format in which SMN-CONAGUA has always handled the data in Mexico, and if other private and public agencies did so too, it would contribute to soil conservation and CA. Moreover, it would help avoid slow, laborious treatment of long term rain intensity data year after year (Diodato 2005; Da Silva 2004). The application of this methodology to shorter time periods (days, months, one year) would be even better under the recommendations of Ziadat, Taimeh (2013), who state that rain intensity is the most important factor affecting soil erosion, which can occur in relatively small-scale areas of moist soil caused by previous rainfall events. In consequence, locating and identifying areas of moist soil and measuring annual, monthly and daily $\mathrm{P}$ can help protect against erosion, and potentially reduce future soil fertility loss and the effects of seasonal dry periods, with resulting benefits to food security and world food subsistence, contributing to meeting the challenges of CA.

\section{Acknowledgments}

The authors thank the two anonymous reviewers whose suggestions and recommendations contributed to enhancing the quality of this research. This manuscript is the result of research undertaken by the first author since the 1980s in northwestern Mexico. He is very grateful to all the people who in any way, directly or indirectly, contributed to achievement of the goals of this work. The authors are fellows of EDI and COFAA; and of SNI-CONACYT. They acknowledge the support of these institutions.

\section{References}

Almoza, Y.; Ruiz, E.; Alonso, G. 2007. Determinación de la erosividad de las precipitaciones en el Oeste de Cuba, Zonas Áridas 11(1): 139-149.

Almoza, Y.; Ruíz, M.; Medina, H. 2009. Cambios climáticos y sus efectos en las pérdidas de suelo en la cuenca del río Cuyaguateje, Revista Ciencias Técnicas Agropecuarias 18(2): 32-39.

Arshad, M.; Martin, S. 2002. Identifying critical limits for soil quality indicators in agro-ecosystems, Agriculture Ecosystems and Environment 88(1): 153-160.

http://dx.doi.org/10.1016/S0167-8809(01)00252-3

Chica, O. M. 2005. La Geoestadística como herramienta de análisis espacial de datos de inventario forestal: análisis espacial de datos de inventario. En: Actas de la I Reunión de Inventario y Teledetección Forestal, Cuadernos de la Sociedad Española de Ciencias Forestales 19(1): 47-55.

SMN-CONAGUA. 2015. Weather data base Northwest México. Mexican National Meteorological Service- Mexican National Water Commission [online], [cited 15 January 2015]. Available from Internet: http://peac-bc.cicese.mx/datosclim/dcbc. php

Da Silva, A. M. 2004. Rainfall erosivity map for Brazil, Catena 57: 251-259. http://dx.doi.org/10.1016/j.catena.2003.11.006

De la Rosa, D.; Moreira, J. M. 1987. Evaluación ecológica de Recursos Naturales de Andalucía. Ed. Agencia de Medio Ambiente. Junta de Andalucía. 192 p.

De Santos, L. N.; De Azevedo, C. M. 2001. A new procedure to estimate the RUSLE $\mathrm{EI}_{30}$ Index based on monthly rainfall data and applied to the Algarve region, Portugal, Journal of Hydrology 250: 12-18. http://dx.doi.org/10.1016/S0022-1694(01)00387-0

Diodato, N. 2005. Predicting RUSLE (revised universal soil loss equation) monthly erosivity index from readily available rainfall data in Mediterranean area, Environmentalist 25: 63-70.

Elaheh, M.; Davood, N.; Mohammad, H.; Ebrahim, P. 2012. Investigating rainfall erosivity indices in arid and semiarid climates of Iran, Turkish Journal of Agriculture and Forestry 36: $365-378$.

Emery, X. 2007. Conditioning simulations of Gaussian random fields by ordinary kriging, Mathematical Geology 39(6): 607623. ISSN 0186-2979.

FAO. 2015. Principios básicos de la Agricultura de Conservación. Organización de las Naciones Unidas para la Agricultura y la Alimentación. Departamento de Agricultura y Protección del Consumidor-Agricultura de conservación [online], [cited 28 April 2015]. Available from Internet: http://www.fao.org/ ag/ca/es/1b.html.

González, H. J. C.; Batalla, R. J.; Cerda, A.; De Luis, M. 2010. Contribution of the largest events to suspended sediment transport across the USA, Land Degradation and Development Journal 21(1): 83-91. http://dx.doi.org/10.1002/ldr.897

Hammer, O.; Harper, D.; Ryan, J. 2001. Paleontological statistics software package for education and data analysis, Paleontología Electronica 4: 9-9.

IBM. 2012. IBM ${ }^{\star} S P S S^{\star}$ Statistics. International business machines and statistical product and service solutions. United States. $25 \mathrm{p}$.

Khosrowpanah, S.; Leroy, F. 2001. Rainfall erosivity factors (R-factors) for selected islands in the federated states of Micronesia. Water and Environmental Research Institute of the Western Pacific University of Guam. Technical Report Number 92. $28 \mathrm{p}$.

Lal, R. 1976. Analysis of factors affecting rainfall erosivity, in International Conference on Soil Conservation and Management in the Humid Tropics, 10 September 1976, International Institute of Tropical Agriculture and Agricultural Research Council of Niger, Ibadan, Nigeria. $54 \mathrm{p}$.

Llanes, C. O.; Norzagaray, C. M.; Muñoz, S. P. 2013. Análisis espectrales en acuiferos del Noroeste de México: El proceso de desertificación en zonas semiáridas. Editorial Publicia. 120 p.

Llanes, C. O.; Norzagaray, C. M; Maya, D. Y.; Muñoz, S. P.; Beltrán, M. F. A.; Murillo, A. B.; Troyo, D. E. 2011. Efectos hidroambientales de la extracción de agua del acuífero del Río 
Sinaloa, Universidad y Ciencia 27(3): 239-249.

Lobo, D.; Gabriels, D. 2005. Assessing the rain erosivity and rain distribution in different agro-climatological zones in Venezuela, Sociedad y Naturaleza Special Issue 1: 16-29.

Mancilla, G. A. 2008. Uso de la ecuación universal de pérdidas de suelo en el campo forestal: apuntes docentes. Facultad de Ciencias Forestales, Departamento de Silvicultura, Universidad de Chile, Chile.

Martínez, M. 2005. Estimación de la erosión del suelo. Secretaría de Agricultura, Ganadería, Desarrollo Rural, Pesca y Alimentación (SAGARPA). México. 156 p.

Morgan, R. P. C. 2005. Soil erosion and conservation. $3^{\text {rd }}$ ed. UK: Blackwell Publishing Ltd. 269 p.

Muñoz, S. P.; Menanteu, L.; Escobedo, U. 2011. Changes in land use and their impact on the coastal zone in northern Sinaloa (Gulf of California, Mexico). Southampton, Boston: Wessex Intitute of Technology. $206 \mathrm{p}$.

Núñez, C.; Pérez, M.; Cuesta, S.; Cabrera, J. 2007. Procesos de degradación del suelo. Grupo de conservación y recuperación de suelos contaminados. Centro De Investigaciones Energéticas Medioambientales y Tecnológicas (CIEMAT). 67 p.

Oñate, V. 2004. Metodología para la evaluación del riesgo de erosión hídrica en zonas áridas y su aplicación en el manejo y protección de los proyectos hidráulicos, Revista electrónica de la REDLACH 1(1): 6-12.

Pérez, A.; Mesa, S. 2002. Estimación del factor de erosividad de la lluvia en Colombia, in Conferencia Internacional: Memorias I Simposio Latinoamericano de Control de Erosión. Corporación Autónoma Regional para la Defensa de la Meseta de Bucaramanga-Sociedad Colombiana de Geotecnia, 12 March 2002, Bucaramanga, Colombia, 18-22.

Petrovsek, G.; Mikos, M. 2004. Estimating the R factor from daily rainfall data in the sub-Mediterranean climate of southwest Slovenia, Journal of Hydrology 49: 869-877.

Ramírez, O. F. A.; Hincapié, G. E. 2009. Riesgo a la erosión en la zona cafetera central del departamento de caldas, Cenicafé 60(2): 173-189.
Seyed, H. S.; Shahla, T. 2015. Development of stational models for estimation of rainfall environment, Land Degradation and Development Journal 24: 582-590.

Shamshad, A.; Azhari, M. N.; Isa, M. H.; Wan, H. W. M.; Parida, B. P. 2008. Development of an appropriate procedure for estimation of RUSLE EI30 index and preparation of erosivity maps for Pulau Penang in Peninsular Malaysia, Catena 72: 423-432. http://dx.doi.org/10.1016/j.catena.2007.08.002

Suffis, J. 2004. Alternative land use systems for controlling water erosion on steep slopes in small watersheds of the Paute River Basin (Ecuador). Universiteit Gent, Gent.

Taguas, E. V.; Carpintero, E.; Ayuso, J. L. 2013. Assessing land degradation risk through the long-term analysis of erosivity: a case study in southern Spain, Land Degradation and Development Journal 24(1)9: 179-187.

Toutcha, L.; Sosa, M.; Soto, R. 2005. La flora de las barrancas del Cobre, Chihuahua, México, Ecología Aplicada 4(12): 17-23.

Wischmeier, W. H.; Smith, D. D. 1960. A universal soil-loss equation to guide conservation farm planning, in International Congress of Soil Science, Trans, November 1960, Madison, Wisconsin, United States, 418-425.

Yu, B.; Hashim, G. M.; Eusof, Z. 2001. Estimating the R-factor with limited rainfall data: a case study from peninsular Malaysia, Journal of Soil and Water Conservation 56: 101-105.

Yuksel, A.; Gundogan, R.; Akay, A. 2008. Using the remote sensing and GIS technology for erosion risk mapping of Kartalkaya dam watershed in Kahramanmaras, Turkey, Sensors 8: 4851-4865. http://dx.doi.org/10.3390/s8084851

Zhu, Q.; Chen, X. W.; Fan, Q. X. 2011. A new procedure to estimate the rainfall erosivity factor based on Tropical Rainfall Measuring Mission (TRMM) data, Science China Technological Sciences 54: 2437-2445. http://dx.doi.org/10.1007/s11431-011-4468-Z

Ziadat, F. M.; Taimeh, A. Y. 2013. Effect of rainfall intensity, slope, land use and antecedent soil moisture on soil erosion in an arid environment, Land Degradation and Development 24: 582-590. http://dx.doi.org/10.1002/ldr.2239

Mariano NORZAGARAY-CAMPOS. PhD. Specializing in groundwater, climate change and water resources. Research Professor at the National Polytechnic Institute at the Interdisciplinary Center of Research for Regional Integral Development (CIIDIR-IPN-Sinaloa). Professor in the Master of Natural Resources and Environment and Conservation, PhD in natural heritage.

Patricia MUÑOZ-SEVILLA. PhD. Specializing in water resources and climate change. Research Professor at the National Polytechnic Institute and Ministry of Research and Graduate Studies. Professor in the Master of Natural Resources and Environment and Conservation, $\mathrm{PhD}$ in natural heritage.

Teresa Leticia ESPINOSA-CARREÓN. PhD. Specializing in physical-biological connections. Research at National Polytechnic Institute. Professor in the Master of Natural Resources and Environment, and Environment and Conservation, $\mathrm{PhD}$ in natural heritage.

Rosario RUIZ-GUERRERO. PhD. Specializing in water resources and analytical chemistry. Research Professor at the National Polytechnic Institute. Professor in the Master in Advanced Technology and PhD in Advanced Technology.

Héctor Abeardo GONZÁLEZ-OCAMPO. PhD. Specializing in environmental impact of human activities and sustainable aquaculture. Research Professor at the National Polytechnic Institute at the Interdisciplinary Center of Research for Regional Integral Development (CIIDIR-IPN-Sinaloa). Professor in the Master of Natural Resources and Environment and Conservation, $\mathrm{PhD}$ in natural heritage.

Omar LLANES-CÁRDENAS. PhD. Specializing in groundwater, climate change and water resources. Research Professor at the National Polytechnic Institute at the Interdisciplinary Center of Research for Regional Integral Development (CIIDIR-IPN-Sinaloa). Professor in the Master of Natural Resources and Environment Conservation. 